\title{
Entering the great unknown: Transition to academic practice
}

\author{
Amy G. Fiedler, MD, ${ }^{\mathrm{a}}$ and Smita Sihag, $\mathrm{MD}, \mathrm{MPH}^{\mathrm{b}}$
}

\footnotetext{
From the a Division of Cardiothoracic Surgery, Department of Surgery, University of Wisconsin, Madison, Wis and ${ }^{\mathrm{b}}$ Division of Thoracic Surgery, Department of Surgery, Memorial Sloan Kettering, New York, NY.

Disclosures: Authors have nothing to disclose with regard to commercial support.

Received for publication June 11, 2019; revisions received Sept 5, 2019; accepted for publication Sept 12, 2019; available ahead of print Oct 21, 2019.

Address for reprints: Amy G. Fiedler, MD, 600 Highland Ave, Madison, WI 53792 (E-mail: fiedler@ surgery.wisc. edu).

J Thorac Cardiovasc Surg 2020;159:1156-60

$0022-5223 / \$ 36.00$

Copyright $(5) 2019$ by The American Association for Thoracic Surgery

https://doi.org/10.1016/j.jtcvs.2019.09.076
}

"The days are long, but the years are short." This is one of the most common quotations echoed throughout the ranks of cardiothoracic surgical trainees during the near decade that most of us spend training. Countless hours are spent at the hospital, in the operating room, and taking care of some of the sickest and most complicated patients in the hospital. Years of education, sacrifice, and dedication to the craft of cardiothoracic surgery, no matter the path chosen, all leads to the same end goal: securing your first faculty position. The first faculty position fills one with excitement and trepidation, all at once. Although our mentors have trained us with skill and dedication to become excellent surgeons, the first faculty position presents a unique set of circumstances for young cardiothoracic surgeons as they assume the role of junior attending from that of trainee. In this editorial, written by 2 early career cardiothoracic surgeons, we detail some of the difficult aspects of the transition to the first faculty position, followed by advice to aid the transition to practice.

\section{TRANSITIONING TO PRACTICE: THE GREAT UNKNOWN}

Transitioning from trainee to an independent practitioner undeniably shifts the individuals' professional identity in a fundamental way. In essence, it is an opportunity to redefine yourself. Literature supports that within the surgical community, a large number of trainees feel ill-prepared for the transition to practice. ${ }^{1}$ Westerman and colleagues ${ }^{2}$ studied trainees from both medical and surgical specialties as they moved into independent roles and found that new faculty struggle with multiple aspects of their new role, including but not limited to taking final responsibility for patient care decisions, managing multiple tasks, training residents, and dealing with and integrating into an unfamiliar workplace. Other researchers have documented a significant fear of failure as young doctors transition to practice, as well as fear of being found to be incompetent in their new role. ${ }^{3}$

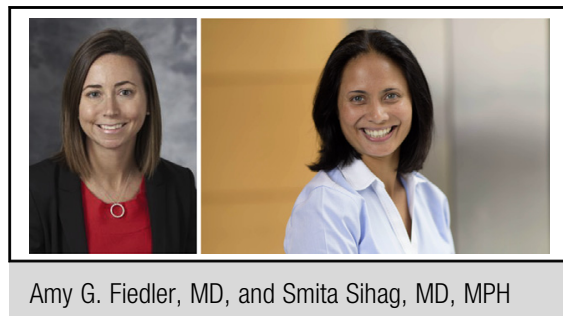

\section{Central Message}

Many skills that allow for a successful transition to practice are not formally taught during training. This article provides advice for trainees as they transition to their first faculty position.

\section{Perspective}

This article is important for young cardiothoracic surgeons moving forward in their career from trainee to junior faculty member. The authors present tips for success that are not formally taught in cardiothoracic training programs for junior surgeons in their first faculty position.

See Commentaries on pages 1161 and 1163.

\section{PATHWAY TO SUCCESS}

While all young cardiothoracic surgeons will ultimately be faced with their own unique challenges associated with their first faculty position, commonalities clearly exist. Here we present specific techniques to help trainees and junior faculty cardiothoracic surgeons early in their career.

\section{Introduce Yourself}

Beginning your career as a young cardiothoracic surgeon, frequently at a new institution, will require that you work and interact with many new colleagues. This can be daunting and anxiety provoking as you acclimate to your new surroundings and build your clinical practice.

Research recently published in the Harvard Business Review demonstrates that even high-level executives face basic challenges in new situations. Surprisingly, the data show that a large number of professionals do "less than their best" in a new workplace environment due to lack of mastery of 3 basic critical skills: introducing yourself, remembering people's names, and asking questions. ${ }^{4}$

For the junior cardiothoracic surgeon joining a new clinical practice, it is important to adequately introduce yourself to your surgical and medical colleagues. Sending a 
brief introductory email to your perceived referral base within the first month of arrival, providing a brief background summation as well as your contact information, will be instrumental in starting your practice on firm ground by allowing your new colleagues to put a "face to the name" when they see you on the wards and clinics. Creating a repository of colleagues within your institution will enhance feelings of inclusion and teamwork in you and your coworkers.

The "three As" of medicine—availability, affability, and ability-certainly apply to the new cardiothoracic surgery faculty member. It is critical that you be expeditious and timely when responding to referring clinicians. Maintaining an open network of communication with referring providers is key to fostering strong and long-lasting relationships with your referral base. Never forget to call the referring physician to update them on how the patient did. The personal touch of a phone call allows the referring provider to place a voice or a face with your name. This is important when you are a new faculty member establishing new connections. This may be easy when outcomes are good, yet becomes more challenging when you have a poor outcome early in your practice.

Being available is not limited to the relationships that you develop with referring providers. When making the transition from trainee to junior faculty, one important aspect that may be underappreciated by residents is the fact that he or she is now the person responsible for continuity of care. With this comes great rewards, as the relationships with your patients and their families that you develop over time will enrich you as a physician. Remaining mindful of this responsibility early on in practice will allow you to develop useful communication skills for establishing effective long-term relationships with your patients.

\section{Remain Flexible and Participatory}

As the junior partner in an established group of surgeons within a specific health system, your practice patterns will likely vary from those in the environment in which you trained. It is critical that as the junior member of the team, you remain flexible in your thought processes and clinical decision making without compromising patient care. Conversations among care team members that are led by the junior attending beginning with "where I trained we did..." can be dull and off-putting to your new group of colleagues and should be avoided when possible.

In addition, participating in multidisciplinary efforts within your specialty will increase your institutional visibility, facilitate research collaboration, and enhance clinical practice-building.

Referring physicians may call you with an urgent need for surgery, knowing that your schedule may be more flexible than that of your senior partners. This is a perfect time to remain flexible, adding on a case either in the evening or a weekend to demonstrate your ability to be a team player. In addition, your senior partners may call on you to help them with a challenging case or even to handle a small case for them while they are busy elsewhere. Participating willingly in these types of situations will only serve to enhance your reputation and build your team.

\section{Get by With a Little Help From My Friends}

Transition to practice can be a socially isolating, stressful period of time in the junior cardiothoracic surgeons' career. As the identity of the young physician shifts from trainee to faculty member, the social norms and peer group also change. This can be a time of upheaval mixed with feelings of social isolation.

Social support has been identified as an important factor in managing stress. In medical workers, support from friends, leaders, and coworkers has been linked to reduced job strain and improved health outcomes. ${ }^{5,6}$ As a result, it is critical that you not lose sight of the relationships with those who have supported you throughout your training process and life before you assumed your first faculty position. Friends made throughout surgical training are likely lifelong relationships, colleagues, sounding boards, and shoulders to lean on during the sometimes trying times faced by an attending cardiothoracic surgeon.

In addition, remaining in close contact and continuing to maintain relationships with your surgical mentors from training is fundamentally important. These individuals are vested in your success and have unique insight into your strengths, weaknesses, and capabilities both as a surgeon and as a person. We encourage young cardiothoracic surgeons to remain in touch with mentors from training to aid in the transition from trainee to faculty member.

One of the personal challenges during the transition to practice is the shift from the predetermined "80-hour work week" to being a 24/7/365 physician for your patients. At the beginning, this transition can be jarring and disruptive. The concept of work-life integration may be more applicable than work-life balance, as there may never be a balance, but integration of work into the surgeon's personal life is key to success and well-being. Antonoff ${ }^{7}$ covered the concept of work-life integration eloquently in a Society of Thoracic Surgeons blog post, defining key points as aligning your time commitments with your priorities, outsourcing what you can, and recognizing the "roller-coaster" with high points and low points in life. Ultimately, feeling well and balanced professionally and personally will benefit your career trajectory and, most importantly, your patients.

Remember that your new partners are also a network of support. Call on their expertise in challenging cases, recognizing that your senior partners want to ensure your success and will help intellectually or technically as needed in difficult cases. 


\section{Do What You Were Hired to Do}

We end up in our first jobs for a variety of reasons. Factors that influence job selection include geographic constraints, spouse or partner preferences, salary and benefits, clinical volume, mentorship, research opportunities, fit within the division, quality of trainees, and so forth. Occasionally, a dream job comes along and a number of these criteria fall nicely into place. During the interview and job offer process, it may or may not have become clear why you were hired to join the group. Either way, it is imperative to figure out why exactly you were hired, and that you prioritize delivering in this domain to ensure success. Every division head, department chair, or group leader has a vision in mind for what gap they want you to fill when you arrive. If you are not already aligned with this goal, we suggest that you carefully consider getting so aligned, at least in the short-term, even if it does not represent your primary aspiration. Whether it is to enhance clinical volume, develop a new program, cover an affiliated hospital, or start a lab, ideally, the goals of your division or chief are the same as you would set for yourself. This is obviously likely to be the most harmonious situation. If you prefer to spend time in the lab but your division chief needs you to take on more clinical volume, bad blood and disappointment are likely to ensue.

In addition, it is important for the junior faculty member to remember that while the inclination will be to say "yes" to most everything, saying "no" is appropriate when asked to participate in committees, research, or other obligations that may detract from your primary focus. The young surgeon should take careful inventory as to how their time is being utilized to ensure that they are working on projects that align with their career and personal goals.

The clinical, research, and call obligations may look very different depending on whether the young surgeon has accepted a position in academia versus the private sector. The incentives, clinical and research expectations, teaching obligations, and case mix will vary dramatically depending on the type of practice the young surgeon enters. While a full discussion surrounding the difference in practice type of an academic versus private practice cardiothoracic surgeon is beyond the scope of this editorial, the young surgeon may reference the informative work by Baimas-George and colleagues $^{8}$ discussing the economics of private practice versus academia in surgery. Additional information for the young cardiothoracic surgeon looking to compare differing practice types can be found via the web transcript of the American Association of Thoracic Surgeons (AATS) Cardiothoracic Careers College, Career Development program (https://www.aats.org/aatsimis/AATSWeb/Association/ Meetings/Annual_Meeting/99th_Annual_Meeting/AATS_ 99th_Annual_Meeting_Sessions/CARDIOTHORACIC_ CAREERS_COLLEGE_CAREER_DEVELOPMENT.aspx).

\section{Identify Your Technical Starting Point, and Grow From There}

Each individual surgeon will have their own unique technical strengths and weaknesses. The ability of the new faculty member to honestly recognize their comfort levels with specific surgical procedures which they will be required to perform is of utmost importance. Antonoff and colleagues ${ }^{9}$ recently published a study evaluating cardiothoracic surgery graduates' perceived readiness for independent practice throughout a variety of areas, but importantly, technical training. They found that despite specialization into either cardiac or thoracic tracking, not all graduates feel prepared to perform what can be classified as standard cardiothoracic surgical cases.

Understanding that not every recent graduate is fully comfortable performing operative cases independently at the beginning of their career, we encourage trainees to discuss formalized mentoring programs during employment interviews. Being a proactive advocate for yourself as you enter your first faculty position will allow you to feel supported in the operating room, while having the opportunity to continuously grow as a surgeon while mastering your craft.

In addition to establishing a mentoring plan for the early portion of your first faculty position, the importance of technical courses supported by industry, such as cadaver labs for new techniques or weekend learning labs for multidisciplinary therapies, should be explored. Funding supplied by the Thoracic Surgery Foundation and AATS may be obtained by the young surgeon to participate in technical mentoring programs for new technologies, such as robotic surgery, or traveling fellowships to support exposure to different techniques. These opportunities not only are helpful from a technical standpoint, but also will serve the junior faculty member in a networking capacity.

One advantage of being the new young surgeon hired into a group is the ability to introduce new technologies, modalities, and approaches to the practice. While the young surgeon has experience with new technology during the training period, introducing new modalities into practice will have a steep learning curve that can be daunting. A challenge that the young surgeon may face is identifying an appropriate mentor for the new modality. We recommend identifying a senior partner at your institution with an interest either in the new modality or the disease process to serve as a trusted mentor initially. In addition, the support provided from industry proctors, your network, and mentors from training should be called on to ensure the safe introduction of a new technology to the practice.

\section{Keep Track of Your Cases and Outcomes: Continuous Self-Reflection}

Regardless of whether you have an interest in quality and safety initiatives at your institution, maintaining your own personal case log and closely tracking your outcomes are 
extremely helpful, for several reasons. First and foremost, it will help you figure out what's working for you and what's not. Are you able to reproduce the operation you were taught to do in residency and deliver consistent outcomes? Then, as you make modifications on what you learned in training, it may help you understand whether these changes are safe and effective. It can also serve as a memory bank for any key insights or new skills learned. With every positive outcome, you will build your confidence as a young surgeon. You may also need to submit a list of your cases to apply for Fellowship in the American College of Surgeons, and may want to review some of them as you prepare for the American Board of Thoracic Surgery (ABTS) exams.

Another very important reason to embrace this exercise is that you may want to bring up particularly favorable outcomes when advocating for yourself in certain situations. For example, patients may ask you directly about what your outcomes are for a given procedure, and providing this information upfront can inspire them to stick with you. In addition, in your annual review with your division or department chair, your outcomes may be reviewed, and you will want to ensure that you fall within expected parameters. Of course, if for some reason you do not, ask a colleague to come in as co-surgeon as you hone your craft. Many institutions track individual surgeon outcomes using various methodologies, as these are increasingly being reported to state databases, Society of Thoracic Surgeons database, and others. Make sure you are aware of what tools are being used to evaluate your outcomes and what specific metrics are being reported. The more you understand about your own practice, the more successful it will be.

Preparing for the ABTS qualifying and certifying examinations is a significant cause of consternation in the first year of practice of the young cardiothoracic surgeon. While most have prepared with formal study and preparation during training, the ability to delegate time and efforts to focused study while at a new institution and building a new clinical practice can be daunting. We suggest that the young cardiothoracic surgeon be diligent with time management during this focused period of study. Set aside dedicated time each day for systematic topic review. Alert your partners of the date of the ABTS examination, and ask senior partners for advice and guidance on topics that may be outside of your current scope of practice. With respect to the certifying examination, we recommend drawing on your network of co-residents, fellows, and new and old mentors to help review clinical scenarios and practice "mock oral"-style review questions. The act of speaking through scenarios will help hone your delivery, promote succinct and to the point thought processing, and enhance your knowledge and understanding of various topics that you may encounter. We found the resources provided in the form of Self- Education Self-Assessment in Thoracic Surgery (SESATS) and the Thoracic Surgery
Residents Association to be invaluable in board preparation.

\section{Transition From Trainee to Trainer}

Many junior cardiothoracic surgeons are eager to teach residents and fellows when starting their first faculty position. Teaching is an opportunity to train the next generation, showing gratitude to the mentors who trained you and contributing in a meaningful way to our specialty. The young cardiothoracic surgeon who joins a practice in which trainees will be present should seek out formalized teaching in surgical education. Programs developed to teach adult learners are effective and thought-provoking. Specifically, the American College of Surgeons sponsors a course on "Surgeons as Educators" in addition to providing countless resources via the Resources in Surgical Education (RISE) website. We caution the very early career cardiothoracic surgeon with respect to "giving up the entire case," as it is critical to develop not only your rhythm, skills, and expertise, but also the confidence of the new team that you have joined. As you establish your clinical practice, your case volume and numbers will be small initially but will grow as you ramp up your practice. Specifically very early on in such technically demanding specialties, focusing on your outcomes, flow of the operation, and technical excellence is critically important.

That said, there are many additional ways to teach and train residents and fellows while you are becoming acclimated from a technical operating standpoint at your new position. As the most junior faculty member, you likely have a bit more time to devote to case-based discussions, as well as technical planning of operations with trainees. We encourage you to take the time to do this with trainees. You may be surprised at how impactful these conversations can be. Also, do not underestimate the significant value of simulation for technical experience. In the field of cardiothoracic surgery, simulation in the form of cardiopulmonary bypass simulation, animal organ block simulation for large open surgery, or vascular anastomosis modules can truly aid in the technical advancement of the trainee, without the need to "give up" the case early on in your career.

Finally, the value of a personal story or anecdote from your own training experience to share with the trainees at your new institution can be beneficial. As a junior faculty member, you are closest in experience to the trainees, and sharing your experiences and insights as you venture through the initial stages of transition to practice has the opportunity to be instrumental in the trainees' development.

\section{CONCLUSIONS}

The transition from trainee to accepting and succeeding at the first faculty position is one of the most exciting yet stressful periods of time in the career of the cardiothoracic surgeon. While we have all devoted many long, hard, yet 
rewarding years to the process of training for this critical first step, there is much that goes unsaid with respect to succeeding in the transition to practice. The tips and tricks presented here for successfully transitioning to practice may serve as a framework and point of reference for the young cardiothoracic surgeon as he or she navigates through the junior faculty stages.

\section{References}

1. Cogbill TH, Shapiro SB. Transition from training to surgical practice. Surg Clin North Am. 2016;96:25-33.

2. Westerman M, Teunissen PW, van der Vleuten CP, Scherpbier AJ, Siegert CE, van der Lee N, et al. Understanding the transition from resident to attending physician: a transdisciplinary, qualitative study. Acad Med. 2010;85:1914-9.

3. Edwards J, Kelly E, Schieman C, Gelfand G, Grondin SC. Do new thoracic surgeons feel ready to operate? Self-reported comfort level of thoracic surgery trainees and junior thoracic surgeons with core thoracic surgery procedures. $J$ Surg Educ. 2011;68:270-81.

4. Rollag K. Succeed in new situations. Harv Bus Rev. 2015;93:112-5.

5. Lindfors PM, Heponiemi T, Meretoja OA, Leino TJ, Elovainio MJ. Mitigating oncall symptoms through organizational justice and job control: a cross-sectional study among Finnish anesthesiologists. Acta Anaesthesiol Scand. 2009;53: $1138-44$.

6. Buddeberg-Fischer B, Klaghofer R, Abel T, Buddeberg C. Junior physicians' workplace experiences in clinical fields in German-speaking Switzerland. Swiss Med Wkly. 2005;135:19-26.

7. Antonoff MB. How busy surgeons can achieve work-life integration. Available at: https://www.sts.org/resources/career-resources/blog/how-busy-surgeons-can-achievework-life-integration. Accessed August 12, 2019.

8. Baimas-George M, Fleischer B, Korndorffer JR Jr, Slakey D, DuCoin C. The economics of private practice versus academia in surgery. J Surg Educ. 2018;75: 1276-80.

9. Antonoff MB, Luc JGY, Patterson GA, Meyers BF, Damiano RJ Jr, Moon MR Graduate subspecialty and perceptions of cardiothoracic surgery training: a 60year retrospective study. Ann Thorac Surg. 2019;107:285-93. 